\title{
Cost-Effectiveness of a Community-Based Approach Intertwined with a Vertical Aedes Control Program
}

\author{
Alberto Baly,* Maria Eugenia Toledo, Veerle Vanlerberghe, Enrique Ceballos, \\ Alicia Reyes, Idalmis Sanchez, Marinelli Carvajal, Rizel Maso, Maite La Rosa, Orestes Denis, \\ Marleen Boelaert, and Patrick Van der Stuyft \\ Instituto de Medicina Tropical "Pedro Kourí," Department of Epidemiology, La Habana, Cuba; Institute of Tropical Medicine, \\ Epidemiology and Disease Control Unit, Department of Public Health, Antwerp, Belgium; Provincial Unit of Surveillance and Vector \\ Control, Santiago de Cuba, Cuba; Instituto de Medicina Tropical "Pedro Kourí," Department of Economics, La Habana, Cuba
}

\begin{abstract}
We compared in a 5-year intervention study the cost-effectiveness of community-based environmental management intertwined with routine vertical Aedes control and of routine vertical control only. At baseline (year 2000), Aedes infestation levels and economic costs for vector control were comparable in intervention and control areas (house index, $2.23 \%$ versus $2.21 \%$ and US $\$ 21$ versus US $\$ 24 / y r /$ inhabitant, respectively). By 2004 , house indices became $0.22 \%$ versus $2.36 \%$ and the costs were 29.8 US \$ versus 36.7 US $\$ / y r /$ inhabitant, respectively. The community cost made up $38.6 \%$ of the total economic cost in 2004 in the intervention areas against $23.5 \%$ in 2000 . The average cost-effectiveness ratio for the intervention period 2001-2004, expressed as the societal cost incurred for the reduction (from baseline) of Aedes foci, was US $\$ 831.1$ per focus in the intervention areas versus US $\$ 2,465.6$ in the control areas. The intervention produced economic savings and health benefits that were sustained over the whole observation period.
\end{abstract}

\section{INTRODUCTION}

Dengue is a viral vector-born disease that has become a major international public health problem in recent years. Dengue prevention depends to a large extent on control of the main vector, Aedes aegypti. This mosquito breeds in waterfilled containers in the (peri-)domestic environment, and elimination of its varied larval habitats is a daunting and costly task. Community participation has been promoted as a venue to make Aedes control more sustainable by securing behavioral change at household and community levels. ${ }^{1-9}$ Some successful pilot experiences were reported, ${ }^{3}$ but their cost and cost-effectiveness have hardly been assessed, ${ }^{10}$ and their sustainability remains debated. ${ }^{8,9}$

In Cuba, dengue prevention has been a political priority since 1981, and the vertical Aedes control program is well resourced. It is managed at the national level by the Ministry of Health $(\mathrm{MOH})$, but room is left for operational decision making at more decentralized levels. Even though it attains adequate coverage of the whole island, the vertical Aedes control program does not succeed in keeping the Aedes indices always below target (house index $<1 \%$ ) in all regions, and localized dengue outbreaks occurred in Santiago de Cuba in 199711 and in Havana City in 2000-2001. ${ }^{12}$ From 2000 onward, the Cuban $\mathrm{MOH}$ has encouraged community-based environmental management to prevent dengue. ${ }^{13,14}$ Between 2000 and 2002, a pilot project in Santiago de Cuba coupled a community-based active participatory approach with the routine vertical Aedes control program. ${ }^{15}$ Significantly better results were obtained in terms of behavioral changes, entomologic indices, and cost-effectiveness than with the vertical Aedes control program alone. ${ }^{15,16}$

Sustainability and cost-effectiveness over time are key issues in community-based Aedes control. The sustainability of the intervention in Santiago de Cuba was addressed by Toledo and others. ${ }^{14}$ The objective of this paper is to compare,

* Address correspondence to Alberto Baly, Instituto de Medicina Tropical "Pedro Kourí," Subdireccion de Epidemiologia, Autopista Novia del Mediodia, Km 61ำ La Lisa, Ciudad de La Habana, Cuba. E-mails: baly@ipk.sld.cu or balygil@yahoo.com over a 5-year period, the cost-effectiveness of the communitybased environmental management approach intertwined with the vertical Aedes control program to the cost-effectiveness of that program alone.

\section{MATERIALS AND METHODS}

Context. Santiago de Cuba is a city with 470,000 inhabitants in the east of Cuba. It is subdivided in nine health zones with a dense Primary Health Care (PHC) network of policlinics and family medicine practices (staffed by doctors and nurses) and is fully covered by the vertical Aedes control program. A dengue epidemic struck the town in $1997,{ }^{11}$ and Aedes infestation has persisted ever since, with house indices between $1 \%$ and $5 \%$, the highest on the island. This led, in 2000, to the launch of a community-based vector control project that was supported by an external research group from the Institute of Tropical Medicine "Pedro Kourí" in Havana. As intervention areas, the coverage areas of 20 family practices were purposively selected in three health zones, among the ones with the highest Aedes levels. The control areas consisted of an identical number of control practice coverage areas in three comparable health zones of the same municipality. The population in the intervention and control areas was 11,520 inhabitants $(2,400$ houses) and 10,920 (2,600 houses), respectively. The activities in the intervention and control areas are summarized below; a detailed description can be found in Toledo and others. ${ }^{14,15}$

The vertical Aedes control program carried out the regular routine Aedes control activities in the intervention and the control areas. They consisted of entomologic surveillance and source reduction through periodic inspection of houses, larviciding (with temephos) of water-holding containers, selective adulticiding (with cipermethrine and clorpiriphus) when Aedes foci were detected, providing health education, and enforcing mosquito control legislation through the use of fines.

In the intervention areas, a community-based environmental management approach was added to the routine vertical Aedes control program. Community working groups (CWGs) were set up to identify local health problems and needs and to subsequently elaborate and implement action plans related 
to Aedes control. These eventually included, among others, household level control of (peri-)domestic larval habitats, eliminating environmental risk in public areas, transforming garbage belts into vegetable gardens, repairing broken water pipes, sealing basements, and manufacturing water container covers. One CWG was formed in the coverage area of each family medicine practice. It incorporated formal and informal leaders and volunteers, as well as family practice staff (living within this neighborhood) and vertical Aedes control program staff. No financial incentives were offered to the members.

The routine vertical Aedes control program activities were stepped up from early 2001 onward in the light of a dengue outbreak in Havana. The intervals between house inspection cycles for larval control were reduced from 22 to 11 days, and defective water tanks were gradually replaced. In the control areas, additional measures were taken: blanket spraying was introduced for adulticiding in a radius of $150 \mathrm{~m}$ around detected Aedes foci, and the $\mathrm{MOH}$ intensified local information, education, and communication campaigns on dengue.

Time horizon and analytical perspective. The time horizon for this study covers 5 years. The project was prepared in 2000 (formative research and baseline assessment) and implemented in 2001-2002. External support was withdrawn early 2003. The community-based activities were sustained in the intervention area with local means during the follow-up period (2003-2004). We collected cost and effectiveness data in the intervention and control areas and compared the costeffectiveness ratios during the respective periods. The analysis was carried out from the perspective of the $\mathrm{MOH}$ and of the society. In the latter perspective, we included the financial cost of the $\mathrm{MOH}$ and the economically valued contributions made by the community.

Data collection and analysis. Costs. We estimated the economic costs per fiscal year using the methodology proposed by Johns and others. ${ }^{17}$ Essentially, we split up recurrent and capital (for goods lasting $>1$ year) $\mathrm{MOH}$ costs and treated the community cost as a separate category. The recurrent $\mathrm{MOH}$ costs included staff salaries (of the vertical Aedes control program staff and of Primary Health Care staff, but accounting only time spent during duty hours), supplies for larval control and spraying, training, social communication, and operating costs. The capital costs included vehicles and equipment. Information was extracted from bookkeeping records of the health zones and obtained through semi-structured interviews with health personnel and direct observation of the control activities. The community cost estimates the value of unpaid community work contributed by community leaders and household-members, but also by $\mathrm{MOH}$ staff participating in community activities during their free time. We estimated these contributions through interviews with all actors and valued them at the wage rate for similar work in the government sector.

The costs in Cuban pesos were standardized at 2000 constant prices using a GNP implicit deflator ${ }^{18}$ and were converted to \$US at the official 2000 exchange rate of 1 peso $=1 \$$ US. We calculated costs per inhabitant for each year by dividing the corresponding societal cost (adding recurrent, capital, and community costs), the MOH cost (subtracting the community cost from the economic cost), the vertical Aedes control program cost (subtracting from the $\mathrm{MOH}$ cost the primary health care costs, i.e., the salary cost of PHC staff for on duty time devoted to vertical Aedes control program activities), and the community cost by the number of inhabitants in the control and intervention areas, respectively.

Effectiveness and cost-effectiveness. We used the larval indices and the number of Aedes foci reported by Toledo and others. ${ }^{14}$ We calculated the average annual number of foci before the intervention (1998-2000), during implementation (2001-2002), and follow-up (2003-2004) and over the period 2001-2004. The difference between the baseline averages and the averages for the subsequent periods constitute the effectiveness measure. The average cost-effectiveness ratio for a given period was calculated by dividing the yearly average costs by the corresponding effectiveness estimates. We calculated incremental cost-effectiveness by dividing the difference in total cost by the difference in effectiveness between the two strategies.

Willingness to pay for or to participate in Aedes control activities and observed household contributions. In 2004, we conducted a cross-sectional questionnaire survey in a random sample of 200 households each in the intervention and in the control areas. One adult per household was selected as respondent. To explore the willingness to pay for and to participate in activities for Aedes control, we used the methods described by Riera. ${ }^{19}$ The declared willingness was compared with the observed household contributions to vector control activities. The sample size was calculated to detect (with $\alpha=0.05$ and $80 \%$ power) a difference of $15 \%$ or more in the proportions of respondents "willing to pay or participate" in both areas. The Fisher exact test and $t$ test were used to compare the groups.

Ethical aspects. The study protocol was approved by the Ethical Committee of the Institute of Tropical Medicine Pedro Kourí, Cuba, and by the national and local health authorities. Community approval was secured during meetings with the community before project implementation. Informed consent was obtained for the interviews conducted with individual actors.

\section{RESULTS}

Cost analysis. During the baseline period, the $\mathrm{MOH}$ costs and the community costs were comparable in both areas (Table 1). Around $48 \%$ of $\mathrm{MOH}$ expenditure was for wages. In control areas, on average 2,534 houses were inspected each month, 1,850 were sprayed, and $300 \mathrm{~kg}$ temephos and $3.0 \mathrm{~L}$ adulticides were consumed. The vertical Aedes control program used 27 full-time equivalent (FTE) personnel. Households spent on average $2.7 \mathrm{~h} / \mathrm{mo}$ in activities related to the vector control. The figures were similar in the intervention areas:2,307 houses inspected, 1,706 sprayed, and $283 \mathrm{~kg}$ temephos and $2.8 \mathrm{~L}$ adulticides consumed. Twenty-three FTEs were used. The average time spent by households was $2.5 \mathrm{~h} / \mathrm{mo}$.

During the implementation period, there was an absolute increase in recurrent costs in both areas because of the shortening of inspection cycles and higher vector infestation levels. The number of houses inspected per month rose to 5,987 and 4,648 in the control and intervention areas, the number sprayed to 2,743 and 1,598 , and employment to 37 and 30 FTEs, respectively. In the control areas, $407 \mathrm{~kg}$ temephos and 4.3 L adulticides were used per month, a substantial increase from the previous period. In the intervention areas, the use of chemicals slightly diminished to $249 \mathrm{~kg}$ and $2.6 \mathrm{~L}$, respectively. In the intervention areas, there was a shift from financial to economic cost: the share of recurrent $\mathrm{MOH}$ costs in the total 
TABLE 1

Average annual economic costs (US\$) for Aedes control in intervention and control areas, Santiago de Cuba, 2000-2004

\begin{tabular}{|c|c|c|c|c|c|c|}
\hline & \multicolumn{3}{|c|}{ Intervention areas } & \multicolumn{3}{|c|}{ Control areas } \\
\hline & $\begin{array}{l}\text { Baseline } \\
2000(\%)\end{array}$ & $\begin{array}{l}\text { Intervention } \\
2001-2002(\%)\end{array}$ & $\begin{array}{l}\text { Follow-up } \\
\text { 2003-2004 (\%) }\end{array}$ & $\begin{array}{l}\text { Baseline } \\
2000(\%)\end{array}$ & $\begin{array}{l}\text { Intervention } \\
2001-2002(\%)\end{array}$ & $\begin{array}{l}\text { Follow-up } \\
2003-2004(\%)\end{array}$ \\
\hline \multicolumn{7}{|l|}{ Recurrent cost } \\
\hline Total & $185,985(76.3)$ & $214,032(63.7)$ & $209,933(61.1)$ & $202,943(77.0)$ & $317,496(79.3)$ & $333,980(83.3)$ \\
\hline Personnel & $117,289(48.1)$ & $137,636(41)$ & $144,493(42.1)$ & $127,706(48.5)$ & $206,622(51.6)$ & $223,116(55.7)$ \\
\hline Vector control staff & $90,471(37.1)$ & $99,946(29.8)$ & $112,439(32.7)$ & $101,188(38.4)$ & $156,149(39)$ & $195,638(48.8)$ \\
\hline Primary health care staff & $26,818(11.0)$ & $37,690(11.2)$ & $32,059(9.3)$ & $26,518(10.1)$ & $50,472(12.6)$ & $27,478(6.9)$ \\
\hline Supplies & $17,354(7.1)$ & $15,776(4.7)$ & $11,048(3.2)$ & $19,542(7.4)$ & $26,853(6.7)$ & $28,821(7.2)$ \\
\hline Training and & & & & & & \\
\hline $\begin{array}{l}\text { communication } \\
\text { Operating cost }\end{array}$ & $6,161(2.5)$ & $13,516(4)$ & $16,868(4.9)$ & $5,877(2.2)$ & $8,706(2.2)$ & $10,064(2.5)$ \\
\hline Operating cost & 45,181 (18.5) & 47,103 (14) & $37,520(10.9)$ & 49,818 (18.9) & $75,315(18.8)$ & $71,979(18.0)$ \\
\hline Capital cost & $458(0.2)$ & $692(0.2)$ & $1,023(0.3)$ & $468(0.2)$ & $1,018(0.3)$ & $1,902(0.5)$ \\
\hline Community cost & $57,303(23.5)$ & $121,168(36.1)$ & $132,424(38.6)$ & $60,075(22.8)$ & $81,963(20.5)$ & $64,973(16.2)$ \\
\hline Total cost & $243,746(100)$ & $335,891(100)$ & $344,390(100)$ & $263,486(100)$ & $400,477(100)$ & $400,855(100)$ \\
\hline
\end{tabular}

cost decreased and community costs increased from $23.5 \%$ to $36.1 \%$. The time invested by households rose to $6.4 \mathrm{~h} / \mathrm{mo}$. In the control areas, the relative share of the different cost items remained the same.

During the follow-up period, the relative shares of the recurrent $\mathrm{MOH}$ costs remained, in both areas, globally at the level of the implementation period. However, salary costs for the vertical Aedes control program staff increased (partly because of the pay raises in 2004), whereas salary cost for PHC staff decreased because of its reduced involvement in Aedes control program activities (many doctors went abroad in that period to work in Cuba's international medical aid schemes). The opposite trend in the cost for supplies, including chemicals, persisted: in the intervention areas, this cost further decreased, whereas in the control areas, it further increased. The community cost remained quite stable in the intervention areas, taking into account the increase in public sector salaries (our basis for valuing unpaid community work). In the control areas, community costs decreased from $20.5 \%$ to $16.2 \%$ of the total cost.

Although economic or societal costs per inhabitant (p.i.) were comparable in both areas at baseline, they had reached, by the end of the implementation period in 2002, \$US 38.2 in the control versus \$US 30.7 in the intervention areas (Table 2).

However, the cost for the community was substantially higher in the intervention areas.

In the follow-up period, the average costs p.i in both areas was quite similar to the ones observed during the implementation period. In particular, the societal, $\mathrm{MOH}$, and vertical Aedes control program costs p.i remained consistently higher in the control areas than in the intervention areas, whereas the community cost p.i was substantially lower in the control areas.
Taken over the 5 years of the study (2000-2004), the MOH cost p.i. remained stable in the intervention areas, whereas in control areas, it increased by $\sim 70 \%$. The community cost doubled in the former areas, whereas it remained fairly stable in the latter ones. The societal cost increased by $40 \%$ and $50 \%$ in intervention and control areas, respectively. This increase is mainly attributable to increasing community costs in intervention areas and to increasing costs of the vertical Aedes control program in control areas.

Effectiveness. No dengue transmission was detected during the study. In the implementation period, both areas showed a similar decrease from baseline in the number of Aedes foci (Table 3). During the follow-up period, the reductions from baseline further increased in the intervention areas, whereas in the control areas, they reverted to levels above baseline.

Cost-effectiveness. From the societal and the $\mathrm{MOH}$ perspectives, the community-based approach intertwined with the vertical Aedes control was more cost-effective during the implementation period (Table 4). It cost less and had similar effectiveness as the vertical Aedes control program only. During the follow-up period, the community-based approach turned out dominant: it was both more effective and less costly. The cost-effectiveness ratio of the vertical Aedes control program alone became negative in this period because there was an increase instead of a reduction in foci respective to baseline.

Taken over the whole period 2001-2004, the incremental cost-effectiveness ratio is negative; the community-based approach dominates the vertical Aedes control program both from the $\mathrm{MOH}$ and from the societal perspectives.

Willingness to pay for or to participate in Aedes control. In the intervention and the control areas, only a minority of households were willing to directly pay for Aedes source reduction, with the notable exception of acquiring a new

TABLe 2

Cost (US\$) for Aedes control per inhabitant per year in intervention and control areas, Santiago de Cuba, 2000-2004

\begin{tabular}{|c|c|c|c|c|c|c|c|c|}
\hline \multirow[b]{2}{*}{ Year } & \multicolumn{2}{|c|}{ Societal cost } & \multicolumn{2}{|c|}{$\mathrm{MOH}$ cost } & \multicolumn{2}{|c|}{ Vertical program cost } & \multicolumn{2}{|c|}{ Community cost } \\
\hline & Intervention & Control & Intervention & Control & Intervention & Control & Intervention & Control \\
\hline 2000 & 21.2 & 24.1 & 16.2 & 18.0 & 13.9 & 16.0 & 5.0 & 5.5 \\
\hline 2001 & 27.6 & 35.2 & 18 & 26.7 & 14.9 & 22.4 & 9.6 & 8.5 \\
\hline 2002 & 30.7 & 38.2 & 19.3 & 31.6 & 15.8 & 26.7 & 11.4 & 6.5 \\
\hline $2001-2002$ & 29.2 & 36.7 & 18.6 & 29.2 & 15.4 & 24.5 & 10.5 & 7.5 \\
\hline 2003 & 29.0 & 35.1 & 18.2 & 29.6 & 14.9 & 26.7 & 10.8 & 5.5 \\
\hline 2004 & 30.6 & 38.3 & 18.5 & 31.9 & 16.2 & 29.8 & 12.2 & 6.4 \\
\hline 2003-2004 & 29.8 & 36.7 & 18.3 & 30.8 & 15.5 & 28.2 & 11.5 & 5.9 \\
\hline
\end{tabular}


TABLE 3

Effectiveness of Aedes control in intervention and control areas, Santiago de Cuba, 1998-2004

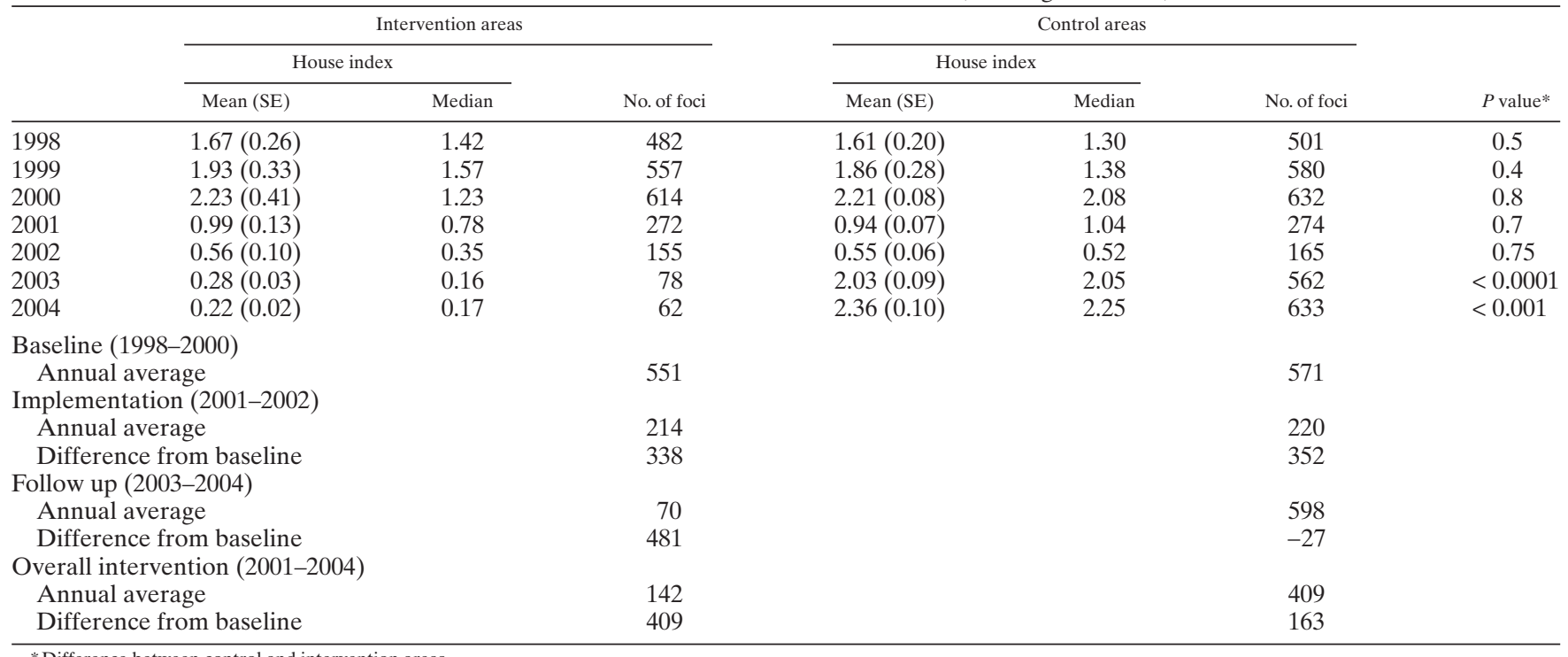

* Difference between control and intervention areas.

hermetic water storage tank (Table 5). However, the amounts that households were willing to invest in a tank were small. On the other hand, households in both areas were quiteand equally-willing to devote time to cooperate with vector control workers during house inspections. However, willingness to spend time to eliminate oneself environmental risks and to attend community meetings was significantly higher in the intervention than in the control areas. In both areas, the household's self-declared willingness to spend time on Aedes control activities was somewhat higher than the actual time spent. Notwithstanding, the actual time spent by households was markedly and significantly higher in the intervention areas.

\section{DISCUSSION}

This study indicates that, in Santiago de Cuba, a communitybased approach intertwined with a routine vertical Aedes control program is more efficient and more effective than vertical control alone, even after the withdrawal of the external support for launching the approach. Although our study was not a randomized community trial, intervention and control areas were comparable at baseline, and there were no differential external influences during the implementation and follow-up period. It is therefore fair to assume that differences in reductions in the number of foci are attributable to differences in effectiveness.

Also very encouraging was the marked and sustained reduction in the use of insecticides and larvicides in the intervention areas. This is clearly a positive environmental outcome that also entails economic advantages, in particular when the chemicals are purchased abroad in hard currency.

As we pointed out previously, the effectiveness of vector control interventions is difficult to determine in non-endemic settings such as $\mathrm{Cuba}^{20}$ because one can not measure changes in dengue incidence rates. Entomologic indices are surrogate markers for epidemic risk, and their functional relationship with the occurrence of dengue outbreaks is not well known..$^{21,22}$ Moreover, in the Cuban context, entomologic indices are very low, and the cost per unit reduction is difficult to interpret. Therefore, we used "average annual difference in foci" as the effect measure. It was derived using routine data that, given the vertical Aedes control program's systematic supervision and quality control, should be reliable. ${ }^{23}$ Furthermore, underestimation of larval prevalence, if any, is expected to be nondifferential.

Whereas in the intervention areas, the number of foci was further reduced in 2003-2004, there was a significant increase

TABLE 4

Cost-effectiveness ratios and incremental cost-effectiveness ratios for Aedes control in intervention and control areas, Santiago de Cuba, 2001-2004

\begin{tabular}{|c|c|c|c|c|c|c|c|}
\hline \multirow[b]{2}{*}{ Perspective } & \multicolumn{3}{|c|}{ Intervention areas } & \multicolumn{3}{|c|}{ Control areas } & \multirow[b]{2}{*}{$\begin{array}{c}\text { Incremental } \\
\text { cost-effectivenes }\end{array}$} \\
\hline & $\begin{array}{l}\text { Average annual } \\
\text { cost }\end{array}$ & $\begin{array}{c}\text { Average annual } \\
\text { effectiveness }\end{array}$ & $\begin{array}{c}\text { Cost-effectiveness } \\
\text { ratio }\end{array}$ & $\begin{array}{l}\text { Average annual } \\
\text { cost }\end{array}$ & $\begin{array}{c}\text { Average annual } \\
\text { effectiveness }\end{array}$ & $\begin{array}{l}\text { Cost-effectiveness } \\
\text { ratio }\end{array}$ & \\
\hline \multicolumn{8}{|l|}{$\overline{\mathrm{MOH}}$} \\
\hline 2001-2002 & 214,723 & 338 & 636.2 & 318,514 & 352 & 906.2 & 7,414 \\
\hline 2003-2004 & 211,966 & 481 & 440.7 & 335,882 & -27 & $-12,674.8$ & -244 \\
\hline 2001-2004 & 213,344 & 409 & 521.3 & 327,198 & 163 & $2,013.5$ & -461 \\
\hline \multicolumn{8}{|l|}{ Society } \\
\hline 2001-2002 & 335,892 & 338 & 995.2 & 400,477 & 352 & $1,139.3$ & 4,613 \\
\hline 2003-2004 & 344,390 & 481 & 716.0 & 400,855 & -27 & $-15,126.6$ & -111 \\
\hline 2001-2004 & 340,141 & 409 & 831.1 & 400,666 & 163 & $2,465.6$ & -245 \\
\hline
\end{tabular}




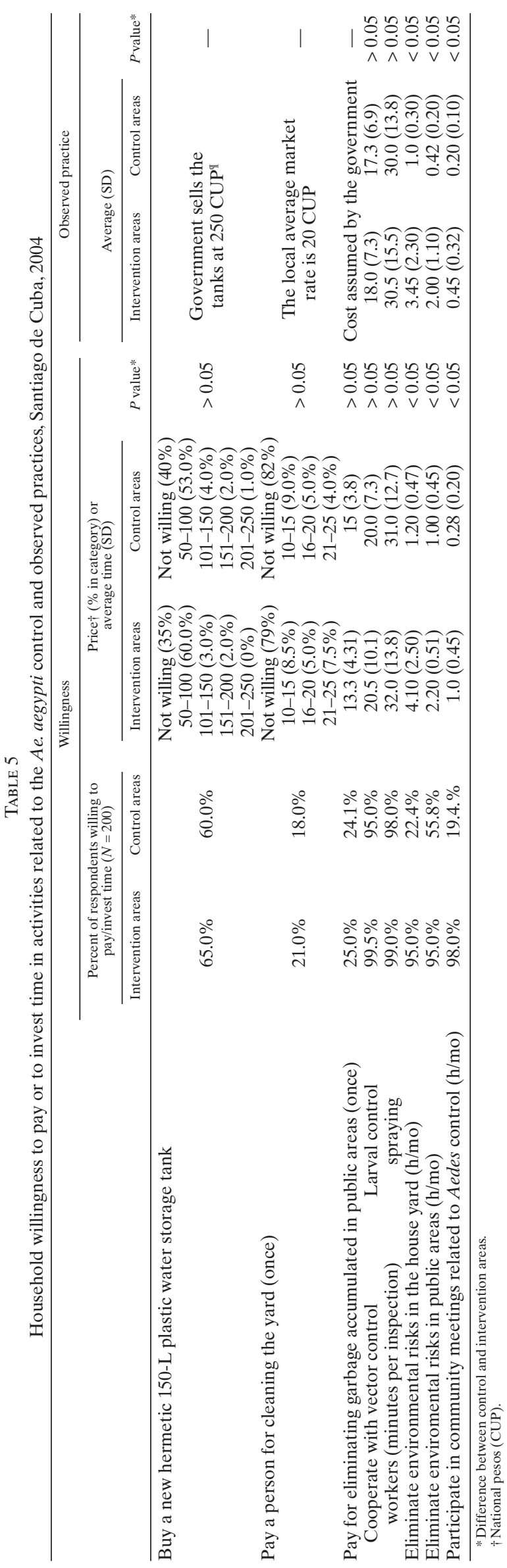

in the control areas. In Santiago de Cuba, environmental risks favor Aedes proliferation in public areas and in the peridomestic environment. The vertical Aedes control program, which has resource constraints during non-epidemic periods, seems unable to eliminate those risks, and it seems to be a good investment to complement its actions with a community-based participatory approach to Aedes control. Notwithstanding, our analysis showed that community participation does not come as a free ride: the costs for the community increases. Additionally, reductions in the number of foci are costly when the levels of infestation are low.

We estimated that the 2004 societal cost of Aedes control in Santiago amounts to \$US30.6 and \$US38.3 per inhabitant for the intervention and control areas, respectively; the vertical Aedes control program cost is \$US16.2 and \$US29.8, respectively. There are very few published studies that have cost Aedes control to compare these figures with. Armien and others ${ }^{24}$ estimated that vector control during the 2005 dengue epidemic in Panama cost US\$1.56 per inhabitant. In Cambodia, ${ }^{25}$ larviciding twice a year with temephos-in accessible water storage containers of $100 \mathrm{~L}$ or more and attaining $23 \%$ coveragecost US $\$ 0.20$ per inhabitant per year. However, a wide array of differences with the above interventions, in terms of developed activities, treatment frequencies, and attained coverage, as well as substantial differences in the epidemiologic backgrounds, preclude direct comparisons with our results. Thus, it is also difficult to extrapolate the cost-effectiveness figures, in particular to endemic countries with high Aedes infestation. Notwithstanding, our results clearly indicate that substantial investments are needed to achieve and maintain successful vector control and that, certainly at low infestation levels, the cost to do better is high. Furthermore, the degree and type of community participation we observed is probably highly dependent on the specific socio-cultural context of Cuba. For example, although households were willing to devote time for vector control, many of them were not willing to spend money for environmental management to maximize the utility (i.e., the subjective benefit) of cash expenditure for other priorities. These contextual differences make it hard to answer questions on the reproducibility of our community approach in different settings.

Nonetheless, our central finding, the higher efficiency of a community-based approach intertwined with a vertical Aedes control program, is generalizable if key elements are recognized and translated in a relevant way to other contexts. Community participation in environmental management activities was set up to favor capacity building and empowerment of vector control workers and community alike and focused on increasing awareness of health benefits and on building new alliances to achieve results. ${ }^{14}$ The community's disposition to participate in control activities can be seen as an increased demand for health care and willingness to contribute to preventive health measures within one's own time and financial limits. Jensen ${ }^{26}$ showed the importance for sustainability of beneficiaries' willingness and ability to pay for health services. Wiesemann and others ${ }^{27}$ showed that participants of educational courses are willing to pay for preventive health measures and this was without correlation with income. Finally, Bossert ${ }^{28}$ and Shediac-Rizkallah and Bone ${ }^{29}$ have identified capacity building as crucial for the sustainability of health programs. Therefore, we believe that vertical Aedes control programs in other countries can effectively tap additional "community resources" to make their actions more 
effective and economically sustainable, on the condition that they invest in raising awareness, building capacity, and in partnerships between the community and the vertical Aedes control program.

Received March 21, 2008. Accepted for publication March 25, 2009.

Acknowledgments: The authors thank the role played by the health sector staff involved in the dengue prevention and Aedes control activities and by the people of Santiago de Cuba who participated in the study. The authors thank Dr. Jose A. Suaya for helpful comments on a draft of the manuscript.

Financial support: The study was funded by the Cuban Ministry of Health and through the framework agreement between the Institute of Tropical Medicine and the Belgian Directorate-General for Development Cooperation (Project 95900).

Authors' addresses: Alberto Baly, Maria E. Toledo, Alicia Reyes, and Idalmis Sanchez, Instituto de Medicina Tropical "Pedro Kourí," Subdireccion de Epidemiologia, Autopista Novia del Mediodia Km 61ำ La Lisa, Ciudad de La Habana, Cuba, Tel: 0053-7-2020652, E-mails: baly@ipk.sld.cu,balygil@yahoo.com, and mariaeugeniatoledo@yahoo .es. Veerle Vanlerberghe, Marleen Boelaert, and Patrick Van der Stuyft, Institute of Tropical Medicine, Epidemiology and Disease Control Unit, Nationalestraat 155, 2000 Antwerp, Belgium, Tel: 0032-32-47-6255, Fax: 0032-32-47-62-58, E-mails: mboelaert@itg.be, vvanlerberghe@ itg.be, and pvdstuyft@itg.be. Enrique Ceballos, Marinelli Carvajal, Rizel Maso, Maite La Rosa, and Orestes Denis, Unidad Provincial de Vigilancia y Lucha Antivectorial, Avenida Garzon, Santiago de Cuba, Cuba, E-mail: vectores@infosol.scu.sld.cu.

Reprint requests: Alberto Baly Gil, Instituto de Medicina Tropical "Pedro Kourí," Subdireccion de Epidemiologia, Autopista Novia del Mediodia, Km 61ํㅡ La Lisa, Ciudad de La Habana, Cuba, Tel: 0053-7. 2020652, E-mails: baly@ipk.sld.cu or balygil@yahoo.com.

\section{REFERENCES}

1. Pai HH, Hong YJ, Hsu EL, 2006. Impact of a short-term community-based cleanliness campaign on the sources of dengue vectors: an entomological and human behavior study. J Environ Health 68: 35-39.

2. Toledo ME, Baly A, Ceballos E, Boelaert M, Van der Stuyft P, 2006. Participación comunitaria en la prevención del dengue: un abordaje desde la perspectiva de los diferentes actores sociales. Rev Salud Públ Mex 48: 1-6.

3. Parks WJ, Lloyd LS, Nathan MB, Hosein E, Odugleh A, Clark GG, Gluber DJ, 2005. International experiences in social mobilization and communication for dengue prevention and control. Dengue Bull 28 (Suppl): 1-7.

4. Renganathan E, Parks W, Lloyd L, Nathan MB, Hosein E, Odugleh A, Clark GG, Gubler DJ, Prasittisuk C, Palmer K, San Martin JL, 2003. Towards sustaining behavioural impact in dengue prevention and control. Dengue Bull 27: 6-12.

5. Kay BH, Nam VS, Tien TV, Yen NT, Phong TV, Diep VT, Ninh TU, Bektas A, Aaskov JG, 2002. Control of Aedes vectors of dengue in three provinces of Vietnam by use of Mesocyclops (Copepoda) and community-based methods validated by entomologic, clinical, and serological surveillance. Am J Trop Med Hyg 66: 40-48.

6. Winch PJ, Leontsini E, Rigau-Perez JG, Ruiz-Perez M, Clark GG, Gubler DJ, 2002. Community-based dengue prevention programs in Puerto Rico: impact on knowledge, behavior, and residential mosquito infestation. Am J Trop Med Hyg 67: 363-370.

7. Chiaravalloti NF, de Moraes MS, Fernandes MA, 1998. Results of activities encouraging community participation in dengue control in an outlying neighborhood of Sao Jose do Rio Preto, Sao Paulo, and the relationship between the population's knowledge and habits. Cad Saude Publica 14 (Suppl 2): 101-109.

8. Gubler DJ, Clark GG, 1996. Community involvement in the control of Aedes aegypti. Acta Trop 61: 169-179.

9. Lloyd LS, Winch P, Ortega-Canto J, Kendall C, 1992. Results of a community-based Aedes aegypti control program in Merida, Yucatan, Mexico. Am J Trop Med Hyg 46: 635-642.
10. Heintze C, Garrido MV, Kroeger A, 2007. What do communitybased dengue control programmes achieve? A systematic review of published evaluations. Trans $R$ Soc Trop Med Hyg 101: $317-325$.

11. Valdes L, Guzman MG, Kouri G, Delgado J, Carbonell I, Cabrera MV, Rosario D, Vazquez S, 1999. Epidemiology of dengue and hemorrhagic dengue in Santiago, Cuba 1997. Rev Panam Salud Publica 6: 16-25.

12. Pelaez O, Guzman MG, Kouri G, Perez R, San Martin JL, Vazquez S, Rosario D, Mora R, Quintana I, Bisset J, Cancio R, Masa AM, Castro O, Gonzalez D, Avila LC, Rodriguez R, Alvarez M, Pelegrino JL, Bernardo L, Prado I, 2004. Dengue 3 epidemic, Havana, 2001. Emerg Infect Dis 10: 719-722.

13. Sanchez L, Perez D, Perez T, Sosa T, Cruz G, Kouri G, Boelaert M, Van der Stuyft P, 2005. Intersectoral coordination in Aedes aegypti control. A pilot project in Havana City, Cuba. Trop Med Int Health 10: 82-91.

14. Toledo Romani ME, Vanlerberghe V, Perez D, Lefevre P, Ceballos E, Bandera D, Baly Gil A, Van der Stuyft P, 2007. Achieving sustainability of community-based dengue control in Santigo de Cuba. Soc Sci Med 64: 976-988.

15. Toledo ME, Vanlerberghe V, Baly A, Ceballos E, Valdes L, Searret M, Boelaert M, Van der Stuyft P, 2007. Towards active community participation in dengue vector control: results from action research in Santiago de Cuba. Trans R Soc Trop Med Hyg 101: $56-63$.

16. Baly A, Toledo ME, Boelaert M, Reyes A, Vanlerberghe V, Ceballos E, Carvajal M, Maso R, La Rosa M, Denis O, Van der Stuyft P, 2007. Cost effectiveness of Aedes aegypti control programmes: participatory versus vertical. Trans $R$ Soc Trop Med Hyg 101: 578-586.

17. Johns B, Baltussen R, Hutubessy R, 2003. Programme costs in the economic evaluation of health interventions. Cost Eff Resour Alloc 1: 1.

18. Naciones Unidas-CEPAL, 2004. Cuba: evolución económica durante 2003 y perspectivas para 2004. Naciones UnidasCEPAL 15: 2004.

19. Riera P, 2004. Manual de valoración contingente. Available at: http://selene uab es/prieram/manual htm. Accessed March 2004.

20. Guzman MG, Pelaez O, Kouri G, Quintana I, Vazquez S, Penton M, Avila LC, 2006. Final characterization of and lessons learned from the dengue 3 epidemic in Cuba, 2001-2002. Rev Panam Salud Publica 19: 282-289.

21. Reiter P, Gubler DJ, 1997. Surveillance and control of urban dengue vectors. Gubler DJ, Kuno G, eds. Dengue and Dengue Hemorrhagic Fever. London: CAB International. 425-463.

22. Focks DA, Brenner RJ, Hayes J, Daniels E, 2000. Transmission thresholds for dengue in terms of Aedes aegypti pupae per person with discussion of their utility in source reduction efforts. Am J Trop Med Hyg 62: 11-18.

23. Sanchez L, Vanlerberghe V, Alfonso L, Marquetti MD, Guzman MG, Bisset J, Van der Stuyft P, 2006. Aedes aegypti larval indices and risk for dengue epidemics. Emerg Infect Dis 12: 800-806.

24. Armien B, Suaya JA, Quiroz E, Sah BK, Bayard V, Marchena L, Campos C, Shepard DS, 2008. Clinical characteristics and national economic cost of the 2005 dengue epidemic in Panama. Am J Trop Med Hyg 79: 364-371.

25. Suaya JA, Shepard DS, Chang MS, Caram M, Hoyer S, Socheat D, Chantha N, Nathan MB, 2007. Cost-effectiveness of annual targeted larviciding campaigns in Cambodia against the dengue vector Aedes aegypti. Trop Med Int Health 12: 1026-1036.

26. Jensen ER, 1991. Cost-Effectiveness and Financial Sustainability in Family Planning Operation Research. Operation Research: Helping Family Planning Work Better. New York: Wiley-Liss.

27. Wiesemann A, Mueller-Buehl U, Scheidt R, Boehme W, Scheuermann W, 2004. Patient willingness to pay for preventive measures in primary care: a study of five GPs in a German community. Soz Praventivmed 49: 254-260.

28. Bossert TJ, 1990. Can they get along without us? Sustainability of donor-supported health projects in Central America and Africa. Soc Sci Med 30: 1015-1023.

29. Shediac-Rizkallah MC, Bone LR, 1998. Planning for the sustainability of community-based health programs: conceptual frameworks and future directions for research, practice and policy. Health Educ Res 13: 87-108. 